\title{
Desafios para a formação docente de jovens e adultos: um olhar para o ensino de Ciências e Biologia
}

\author{
Cibele Barbosa de Araujo Santana Nilo ${ }^{1}$ \\ Marco Antonio Leandro Barzano ${ }^{2}$
}

\begin{abstract}
Resumo
O artigo analisa dificuldades enfrentadas por licenciandos e recém-egressos do curso de Licenciatura em Ciências Biológicas ao ensinarem Ciências e Biologia nas escolas para o público da Educação de Jovens e Adultos. Apresentamos resultados de uma pesquisa qualitativa estruturados em duas partes: uma reflexão teórica sobre a Educação Jovens e Adultos no ensino de Ciências e Biologia, em que é relatada a experiência de um professor de Ciências e Biologia em uma escola rural no Rio de Janeiro; e uma pesquisa desenvolvida sobre o Projovem Urbano. Tais resultados apontam que ainda há severas dificuldades ao trabalhar a EJA, sobretudo no que se refere à formação no curso de Licenciatura em Ciências Biológicas, e que isso pode influenciar diretamente a qualidade do ensino nas escolas.
\end{abstract}

Palavras-chave: Educação de Jovens e Adultos; Formação Docente; Ensino de Ciências e Biologia.

\section{Challenges for teacher education for young people and adults: a look at the teaching of Science and Biology}

\begin{abstract}
The article analyzes difficulties faced and their implications by undergraduates and recent graduates to teach Science and Biology in schools with the public in the education of young people and adults (EPJA). We present results of a qualitative research structured in two parts: a theoretical reflection on the education of young and adult people in the teaching of Science and Biology, in which the experience of a Science and Biology teacher in a rural school in Rio de Janeiro is reported and a research that developed on the urban Projovem. Such results indicate that there are still severe difficulties when working at EPJA, especially with regard to training in the Biological Sciences teacher training and that this can directly influence the quality of teaching in schools.

Keywords: Education of Young and Adult People; Teacher Education; Science and Biology Teaching.
\end{abstract}

\section{Considerações iniciais}

Os últimos anos da última década têm sido nebulosos no que diz respeito aos aspectos políticos, sociais, econômicos, assim como aos culturais e éticos. No campo da educação, isso não é diferente, muito menos no que se refere à Educação de Jovens e Adultos (EJA) e, mais especificamente, à formação docente para atender a esse público.

O desmonte da educação pública e de sua infraestrutura, a precarização do trabalho

\footnotetext{
${ }^{1}$ Universidade Estadual de Feira de Santana, Feira de Santana, bele_bio@hotmail.com

2 Universidade Estadual de Feira de Santana, Feira de Santana, malbarzano@uefs.br 
docente, além do aceno à privatização e ao fechamento de escolas são apenas alguns dos aspectos que nos convocam a ir à luta, porém, cheios de esperança, pois, como nos ensina Paulo Freire (1994), somos movidos por ela. A luta com esperança não nos permite somente esperar de maneira passiva, mas, de maneira dinâmica, nos move a esperançar.

Mais do que apresentar os resultados de nossas pesquisas e experiências na formação docente, o objetivo deste artigo também é romper com o "epistemicídio" (SANTOS, 1996), fazendo valer a necessidade de trazermos a EJA para a centralidade, visibilidade, retirando-os(as) do currículo das margens (BARZANO, 2016), pois é imperativo mostrar que esses sujeitos subalternizados também podem escrever uma nova história para a sociedade em que vivemos, para a educação, a didática, o currículo, a formação docente.

Nas primeiras décadas do século XXI, temos visto aquilo que podemos considerar como potente no que diz respeito a outros modos de ensinar e aprender Biologia e de compreender aquilo que se curriculariza no cotidiano das aulas dessa disciplina escolar. De uma certa maneira, essa potência apenas reforça aquilo que já tem sido proposto desde a década de 80 do século XX: uma visão menos tecnicista, naturalizada, biologizada, focada em bases cognitivistas, e mais social, cultural, econômica e ética.

O artigo apresenta e analisa, em um primeiro momento, as dificuldades enfrentadas por licenciandos(as) e recém-egressos(as) do curso de Licenciatura em Ciências Biológicas ao ensinarem Ciências e Biologia nas escolas para o público da EJA. Desse modo, apresentamos: (a) uma reflexão teórica sobre a EJA no ensino de Ciências e Biologia, relatando a experiência de um professor de Ciências e Biologia em uma escola rural no Rio de Janeiro; e (b) uma pesquisa que desenvolvemos sobre o Projovem Urbano ${ }^{3}$. Em síntese, os resultados apontam que ainda há severas dificuldades ao trabalhar a EJA, sobretudo no que se refere à formação no curso de Licenciatura em Ciências Biológicas, e que isso pode influenciar diretamente a qualidade do ensino nas escolas.

\footnotetext{
${ }^{3}$ Programa Nacional de inclusão de jovens criado com o intuito de aumentar o grau de escolaridade dos jovens, visando ao desenvolvimento humano e ao exercício da cidadania, por meio da conclusão do Ensino Fundamental, da Qualificação Profissional e do desenvolvimento de experiências de Participação Cidadã. BRASIL. Projovem Urbano. Manual do educador: orientações gerais. Brasília. Programa Nacional de Inclusão de Jovens - Projovem Urbano, 2012.
}

Periódico Horizontes - USF - Itatiba, SP - Brasil - e020059 


\section{Narrativa de um professor em contato com a Educação de Jovens e Adultos}

Era o ano de 1993, e o professor de Ciências, recémformado, se apresentou na escola na zona rural de um município no estado do Rio de Janeiro. O diretor, ao ver aquele jovem de vinte e poucos anos, disse: "você teve sorte, rapaz! Já concluímos a distribuição de horários e você vai ensinar para quatro turmas de sexta série ${ }^{4}$, sendo duas turmas no turno vespertino e duas turmas no noturno, para a EJA. Então, você necessitará trabalhar na escola apenas às terças $\mathrm{e}$ quintas, entrando às 16 horas e saindo às 20 horas, e o melhor: você só precisará fazer apenas um planejamento!". ${ }^{5}$

Tomamos essa epígrafe para abrir a seção, iniciando a partir dela uma reflexão acerca daquilo que consideramos um equívoco ao tratarmos sobre a EJA: considerar que o planejamento do ensino regular seja o mesmo para a EJA. Ainda que as turmas sejam do mesmo ano escolar, no ensino regular ou mesmo na EJA, os planejamentos devem ser diferenciados, levando-se em consideração a realidade do estudante, pois, como afirma Oliveira $(2007$, p.88): “[...] a idade e vivências social e cultural dos educandos são ignoradas, mantendo-se nestas propostas a lógica infantil dos currículos destinados às crianças que frequentam a escola regular".

Concordamos com Cassab (2016, p.20) quando assevera:

[...] os currículos em Ciências e Biologia na EJA por sua vez não devem ser concebidos e analisados com base em um olhar que os identificam plenamente com o currículo do ensino "regular". Afinal, trata-se de outros sujeitos e outras finalidades educativas. [...] É preciso enfrentar o desafio de pensar e produzir currículos voltados à Educação em Ciências e Biologia sintonizados com as especificidades dessa modalidade de ensino. Mais especificamente na pesquisa com a EJA, é preciso forjar um olhar analítico também atento a essas especificidades.

\footnotetext{
${ }^{4}$ Em 1993, utilizava-se a terminologia de série. Após a LDB 9394/96, passou-se a utilizar o termo "ano". Hoje, a sexta série é o sétimo ano.

${ }^{5}$ Episódio que ocorreu com o segundo autor do presente artigo quando ele viveu seu primeiro dia da profissão docente.
}

Periódico Horizontes - USF - Itatiba, SP - Brasil - e020059 
O caso relatado na escola rural nos mostra dois aspectos que consideramos importante apontar neste artigo: (a) a lacuna sobre a EJA no currículo do curso de Licenciatura em Ciências Biológicas (bem como na maioria das demais Licenciaturas), ou seja, a cada ano há centenas de professoras e professores sendo formados(as) sem o embasamento mínimo para atuação na EJA; e (b) a falta de uma efetiva formação continuada de professores(as).

Com o objetivo de conhecermos as publicações sobre EJA e Ensino de Ciências e Biologia (ECB), realizamos um levantamento na plataforma Scientific Electronic Library Online (Scielo) ${ }^{6}$ e constatamos que, dos noventa e dois artigos encontrados a partir do descritor "Educação de Jovens e Adultos", apenas quatro se referiam ao ECB, sendo que nenhum deles abordava a formação docente. No campo das "Ciências da Natureza", a maior parte dos artigos era da Educação Matemática (10) e Física (4); não sendo encontrado nenhum artigo sobre o ensino de Química. A maior parte dos trabalhos, como já era esperado, voltou-se para Pedagogia, Alfabetização e Letramento, além de discussões sobre políticas públicas e evasão escolar. Chamou-nos a atenção que seis artigos foram publicados sobre privação de liberdade ou sistema prisional, mostrando-se como um tema em ascensão na área.

A partir da experiência como formador de professores(as), atuando no curso de Licenciatura em Ciências Biológicas de uma universidade pública baiana, além de ter orientado algumas pesquisas sobre juventude, temos constatado a necessidade urgente de o tema EJA ser encarado e inserido no currículo dos cursos de Licenciatura, pois, conforme constatamos na literatura, somente no curso de Pedagogia há essa predominância curricular.

Temos observado a cada ano o descontentamento de estudantes da Licenciatura no momento em que estão matriculados na disciplina de Estágio Supervisionado e se veem sem condições formativas para atuar nas classes de EJA; como atesta Reis (2012, p.2), ao examinar três cursos de Licenciatura em Ciências Biológicas de universidades públicas baianas, sobretudo no que se refere à disciplina de Estágio Supervisionado:

Durante a graduação do curso de Ciências Biológicas, acredita-se que pouco se explora sobre as questões relacionadas à prática pedagógica na sala de aula, principalmente a respeito da Educação de Jovens e Adultos (EJA), transformandoa numa realidade que pode espantar um professor recém saído da academia.

\footnotetext{
${ }^{6}$ Levantamento realizado em 15 de fevereiro de 2020.
} 
A partir da análise de relatórios finais da disciplina de Estágio Supervisionado, os(as) licenciandos(as) revelam, em sua maioria, a importância de assumirem o desafio de estagiar na EJA, mesmo sem condições prévias do "saber docente" que poderia ter sido adquirido ao longo do curso, por se sentirem desafiados(as) na atuação docente. Os relatos orais e escritos desses(as) estudantes mobilizaram os(as) professores(as) da disciplina em uma universidade pública baiana ${ }^{7}$, no momento da reformulação curricular do curso de Licenciatura em Ciências Biológicas, a formularem uma proposta de criação da disciplina de Estágio Supervisionado com enfoque na EJA.

É imperativo destacar que a lacuna existente no currículo do curso de Licenciatura em Ciências Biológicas afeta sobremaneira a atuação de licenciandos(as) nos programas de formação docente, seja no Programa Institucional de Bolsa de Iniciação à Docência (PIBID) ou na Residência Pedagógica (RP). Ressalta-se, porém, que temos constatado, a partir de nossa atuação docente, que alguns(mas) licenciandos(as), mesmo com dificuldades e desafios encontrados, inspiram-se na atuação formativa para a produção de Trabalho de Conclusão de Curso (TCC).

Em sintonia com a obra de Santos (2004), em que o autor aborda sobre a universidade do século XXI, consideramos necessário apontar o papel da universidade na formação profissional de futuros(as) professores(as) de Ciências e Biologia para atuação na EJA, sobretudo para atender as classes populares, sujeitos que, predominantemente, compõem as salas de aula da EJA. Desse modo, é possível vislumbrar um ensino de Ciências e Biologia voltado para a diminuição das desigualdades sociais e que possa colaborar para que os(as) licenciandos(as), no exercício docente, contribuam para a melhoria da qualidade de vida das pessoas e o exercício da cidadania.

Mesmo após vinte anos de um novo século, ainda podemos encontrar currículos dos cursos de Licenciatura, em especial de Ciências Biológicas, que possuem uma abordagem, sobretudo nas disciplinas pedagógicas, voltada para o ensino regular de escolas públicas e privadas, que atendem um público da classe popular e média, matriculados na série com idade prevista em lei. Isso se distancia, inclusive, das abordagens específicas dos conteúdos a serem ensinados, pois, para estudantes da escola regular, o propósito, geralmente, recai em uma

\footnotetext{
${ }^{7}$ Trata-se de uma universidade pública em que um dos autores deste artigo é professor. 
formação da Educação Básica que possibilite o ingresso no Ensino Superior, e isso, na maioria das vezes, não é prioridade para o público de estudantes da EJA, ainda que nossa defesa seja a de que esses(as) estudantes tenham as mesmas condições de acesso à universidade.

É necessário que os(as) licenciandos(as) possuam condições para atuar na EJA, a fim de que não pensem, assim como foi dito, equivocadamente, pelo diretor da escola, que o planejamento da sexta série deve ser apenas um só. O público da EJA possui singularidades que devem ser respeitadas, e a escola deverá criar condições específicas para atender esse público.

Constatamos, desse modo, que a universidade do século XXI, como nos ensina Santos (2004), deverá reestruturar o currículo dos cursos de Licenciatura, para que eles possam ter condições de reelaboração do conhecimento e, sobretudo, para que atendam aos reais interesses das pessoas jovens e adultas. Além disso, é importante que se destaque, do ponto de vista da didática, os modos diferenciados de se planejar as aulas e de proceder à avaliação, tendo em vista que um modo de avaliar o conteúdo ensinado no sétimo ano do turno matutino, voltado, muitas vezes, para a avaliação externa de larga escala, como o Exame Nacional do Ensino Médio (Enem), por exemplo, não pode (nem deve) ser semelhante ao modo de avaliar o estudante da EJA.

Cientes da necessidade de reformulação curricular da Licenciatura, concordamos com Oliveira (2007, p.93), quando mostra que devemos

[...] superar esse entendimento formalista e cientificista do currículo, buscando entendê-lo como oriundo de múltiplos e singulares processos locais de tessitura curricular, requer o estudo e o interesse no fazer aparecer as alternativas curriculares efetivas construídas cotidianamente pelos sujeitos das práticas pedagógicas, e já em curso em muitas escolas/classes do Brasil inteiro. Uma prática curricular consistente somente pode ser encontrada no saber dos sujeitos praticantes do currículo, sendo, portanto, sempre tecida em todos os momentos e escolas/classes.

Ainda com a autora, questionamos: "que conteúdos são necessários para jovens e adultos que buscam uma escolarização tardia? A resposta poderia ser a de que os conteúdos necessários são aqueles que podem ser utilizados na vida cotidiana como meio para a autonomia do sujeito" (OLIVEIRA, 2007, p.98).

Em uma aula de Estágio Supervisionado que, ao mesmo tempo, foi uma oficina para a 
produção de dados do TCC de uma licencianda em Ciências Biológicas (LIMA, 2017), buscamos apostar em uma aula de Ciências com o conteúdo de botânica. Em um primeiro momento, foi organizada uma intervenção em forma de oficina, como propõem Costa, Lima e Braga (2013), com o objetivo de melhorar o ensino de botânica na EJA, já que a literatura comprova que o ensino de botânica possui muitos conceitos a serem memorizados (FLORES, 2014), e isso implica, muitas vezes, a repulsa dos(as) estudantes em relação à botânica.

Após a realização da oficina, houve a organização de uma exposição que seria, além da culminância dos conteúdos aprendidos a partir da realidade dos(as) estudantes, um momento para apresentá-los à comunidade escolar. A montagem e a curadoria da exposição foram realizadas pelos(as) próprios(as) estudantes, que se envolveram também como monitores para apresentação da exposição ao público visitante, conforme é descrito a seguir:

A exposição aconteceu na própria sala de aula e dividida em quatro sessões: "A botânica em nosso dia-a-dia", em que um estudante apresentava aos visitantes do que se tratava a exposição; "A botânica na alimentação", momento em que foi exposto alguns produtos de origem vegetal que utilizamos em nossa alimentação; "Medicina popular", espaço em que trazia um pouco das diversas espécies vegetais que são utilizadas para o tratamento de sintomas de algumas doenças e que, em sua maioria, estão plantadas nos quintais das casas dos estudantes; e, por fim, o "Mural de fotos", que continha todas as imagens capturadas pelos estudantes, quando proposto que eles fotografassem a botânica em seu cotidiano. (LIMA, 2017, p.45).

Em um momento de avaliação sobre a atividade expositiva, uma aluna relatou: "É muito bom pró ${ }^{8}$, porque sei que eu fiz alguma coisa boa (risos), pelo menos, depois de tantos anos sem eu ir pra escola e voltei pra escola e logo no primeiro ano, eu consegui fazer alguma coisa que eu tô vendo que deu resultado e isso é bom demais (risos)" (LIMA, 2017, p.50).

Encerramos esta seção defendendo que as aulas de Ciências e Biologia podem ser encharcadas de singularidades, permitindo que pessoas jovens e adultas possam ter acesso ao conhecimento científico de maneira prazerosa, conforme o relato supracitado. É imperativo que haja a promoção de tal singularidade na formação inicial de professores(as), bem como na formação continuada para professores(as) da EPJA. A exemplo do que ocorreu na culminância

\footnotetext{
8 "Pró" é a maneira afetiva com que estudantes da Educação Básica, na Bahia, se referem às suas professoras.
} 
da exposição, que essa atividade não se restrinja apenas a aulas "diferenciadas", mas que possa também orientar a elaboração das aulas regulares.

Na próxima seção, apresentaremos uma parte da pesquisa com enfoque no Projovem Urbano, refletindo sobre a importância desse programa que foi promovido pela extinta Secretaria de Educação Continuada, Diversidade e Inclusão (Secadi) do Ministério da Educação (MEC).

\section{O Projovem Urbano e as ciências da natureza: apontamentos para pensar a formação docente}

O Programa Nacional de Inclusão de Jovens (Projovem) foi implantado em 2005, por meio de uma iniciativa do Governo Federal, com o intuito de diminuir o quadro de analfabetismo funcional e a exclusão do mercado de trabalho, além de apoiar a emergente necessidade de inclusão de jovens em situação de vulnerabilidade social.

A gestão desse programa coube à Secretaria Nacional da Juventude, sendo partilhada com o Ministério da Educação, o Ministério de Desenvolvimento Social e o Ministério do Trabalho e Emprego. Em 2007, o Projovem tornou-se referência, nascendo, então, o Projovem Integrado, que abarca o Projovem Adolescente, o Projovem Campo, o Projovem Trabalhador e o Projovem Urbano.

Porém foi apenas no ano de 2012 que o programa foi vinculado à estrutura do Sistema Educacional Brasileiro, sendo compreendido como uma modalidade de EJA, vinculada à Secretaria de Educação Continuada, Alfabetização, Diversidade e Inclusão (Secadi) do MEC.

O Projovem em que desenvolvemos a pesquisa, no município de Feira de Santana, estado da Bahia, foi desenvolvido pela Secretaria Municipal de Educação em parceria com o Ministério da Educação. O Programa teve início no ano de 2009, quando houve uma seleção de educadores(as) para atender as oitenta turmas formadas, com um total de 3.200 alunos matriculados e 113 educadores(as) formados(as) para ministrarem aulas de Língua Portuguesa, Matemática, Ciências da Natureza, Ciências Humanas, Inglês, além de Participação Cidadã e Qualificação Profissional.

De acordo com o Manual de Orientações Gerais do programa (SALGADO; AMARAL, 2012), 
o Currículo do Projovem Urbano é estruturado consoante a ideia de que ele se encontra em constante processo de transformação:

\begin{abstract}
As ideias mais atuais veem o currículo, não como algo feito, mas como algo que se faz ao longo do tempo, e é essa concepção que se adota no Projovem Urbano, considerando-se o currículo como um processo que envolve escolhas, conflitos e acordos que se dão em determinados contextos - como os órgãos centrais de educação ou as próprias escolas - com a finalidade de propor o que se vai ensinar (SALGADO; AMARAL, 2012, p.27).
\end{abstract}

Oliveira (2007) afirma que, geralmente, a intenção predominante das propostas curriculares é a de fragmentação do conhecimento, e a de organização do currículo em uma perspectiva cientificista, demasiadamente tecnicista e disciplinarista, que impede conversações entre as experiências vividas, os saberes trazidos pelos educandos e os conteúdos escolares, compreendendo, assim, que os critérios e maneiras de seleção e organização curricular não buscam dialogar com os saberes, nem com os anseios e perspectivas dos jovens a que se destinam.

E, além disso, a organização e seleção de conteúdos, na maioria das propostas curriculares, diversas vezes não acompanha, em nenhum momento, a complexidade do estar no mundo, da vida cotidiana e das aprendizagens que nela ocorrem. Reiteramos que isso acontece tanto no currículo escolar quanto nos cursos do Ensino Superior e, em especial, nas Licenciaturas. Nesse aspecto, a formação docente para atender o público estudantil da EJA sempre fica comprometida.

No entanto, sabemos que, apesar de todas essas dificuldades e barreiras, a vida real nas escolas incorpora no seu cotidiano as experiências, saberes e possibilidades dos sujeitos envolvidos na prática cotidiana do ensinar/aprender, a qual não ocorre apenas em função das propostas e prescrições curriculares que são formuladas. Temos visto essa dinâmica em muitas escolas com que temos parceria, seja a partir de nossa experiência com Estágio Supervisionado, PIBID e Residência Pedagógica, seja em Programas como o Projovem Urbano, que foi objeto de nossa pesquisa.

O Manual de Orientações Gerais do Programa adota como ideia de currículo algo a ser construído ao longo do processo, por meio do qual os praticantes do currículo ressignificam seus 
experimentos a partir das tramas de poderes, saberes e fazeres das quais fazem parte (OLIVEIRA, 2007). Porém, especificamente em relação ao Projovem, tal processo não acontece, pois os(as) professores(as) e alunos(as) envolvidos(as) no Programa receberam um material didático composto de seis guias de estudo (mais o material de qualificação profissional) que contemplam os conteúdos de todas as disciplinas, a serem seguidos rigorosamente, de modo que os(as) alunos(as) possam ser bem-sucedidos(as) na avaliação escrita, que acontece ao final de cada unidade formativa.

Desse modo, há um descompasso entre aquilo que o(a) professor(a) obteve na formação inicial, pois aprendeu a ter autonomia no planejamento, desenvolvimento das aulas e avaliação, e a experiência docente no Projovem, quando percebemos que essa autonomia não é contemplada.

Em relação ao material de Ciências da Natureza, o intuito foi abordar os assuntos associados ao conhecimento do mundo que nos cerca, como o estudo da água, conforme é mostrado a seguir:

Neste segundo volume, vamos tratar da água, esse líquido tão importante para a vida humana. Você verá como ele faz parte do nosso corpo, como chega até nós e como deve ser tratado para não faltar no futuro. Discutindo essas questões, terá oportunidade de entrar em contato com a Biologia, a Física, a Química (SALGADO; AMARAL, 2012, p.14).

Anterior aos capítulos dos assuntos, o guia apresenta algumas contribuições em relação ao modo como os assuntos referentes às Ciências da Natureza podem ajudar na vida do(a) jovem estudante:

No estudo das outras seções deste Guia de Estudo, você está tendo a oportunidade de pensar e discutir com seus colegas sobre a sua história de vida, sobre o lugar em que vive e até mesmo sobre alguns dos problemas enfrentados pela juventude do nosso país, principalmente nas grandes cidades. Agora, não vamos falar apenas da sua cidade ou do seu bairro. Vamos também falar um pouquinho sobre o mundo em que você vive. Você já reparou que as pessoas têm andado mais preocupadas com o ambiente ultimamente? [...] Neste tópico, vamos dar atenção especial à água, e você verá que este é um assunto que tem tudo a ver com você, com seus hábitos e com sua comunidade (SALGADO; AMARAL, 2012, p.226). 
Isso posto, percebemos, por meio do conteúdo do referido capítulo, a importância da presença de aspectos da vida cotidiana e social do(a) estudante, revelando a necessidade da construção da democracia entre cidadãos conscientes de seus direitos e deveres, preparados a opinarem a respeito das finalidades da ciência e tecnologia, bem como sobre a influência delas em suas vidas.

É concebível afirmarmos que o ensino de Ciências na escola muitas vezes oscila entre uma preocupação mais acadêmica, de caráter conteudista e conceitual, e outra mais utilitária, voltada para a formação do cidadão. Logo, entende-se que o ensino dessa área apresenta, como uma de suas principais finalidades, a formação do cidadão cientificamente alfabetizado, capaz não só de identificar o vocabulário da ciência, mas também de compreender conceitos e utilizá-los para enfrentar desafios e refletir sobre seu cotidiano (KRASILCHIK; MARANDINO, 2007).

Acrescentamos que, no intuito de querer participar de forma efetiva na sociedade, é preciso que o sujeito seja sensível na identificação e compreensão das questões, assim como nas barreiras e nas perspectivas das dificuldades levantadas, a fim de se tornar mais capaz de tomar decisões, fundamentadas de maneira responsável e conforme seus valores e posturas éticas.

O conhecimento é tido como uma das bases fundamentais na análise das questões controversas que incluem conflitos de interpretações e decisões, dependentes de valores pessoais e sociais. Dessa forma, a preparação do cidadão para questões conflitantes requer que esteja cientificamente alfabetizado. Por conta do crescimento da ciência e tecnologia, bem como de situações conflitantes éticas e ambientais, é de suma importância que os cidadãos tenham condições de utilizar seus conhecimentos para basear seus posicionamentos e ações.

Reconhecemos que, no material pedagógico do Projovem Urbano, há um currículo que foi inventado para atender especificamente um público de jovens da classe popular que vive em condições de vulnerabilidade.

Constatamos que, de maneira semelhante ao que ocorre com as escolas regulares, o Projovem Urbano, sendo uma modalidade de EJA, apresenta uma determinada concepção relativa à função social da educação e à qual cidadão o Programa propõe formar. No entanto a dimensão da cidadania que é mostrada é a de conquista de direitos, já que o Programa foi pensado para uma parcela da população que se encontra em situação de exclusão e sem acesso a direitos sociais básicos. 
Do ponto de vista técnico, reconhecemos a proposta pedagógica do Projovem Urbano como inovadora. Ela nos leva a refletir acerca dos tempos e espaços pedagógicos dos modelos convencionais, além de possibilitar a experiência de um currículo integrado, que contempla Educação Básica, qualificação profissional e participação cidadã.

No entanto, embora pensado como algo a ser construído e inovador, o currículo analisado carrega alguns elementos que contradizem seu discurso. Percebemos, por exemplo, especificamente em Ciências da Natureza, que, ao mesmo tempo em que o guia traz elementos para a formação cidadã do estudante, a valorização do fazer ciência é fortemente carregada do tradicionalismo científico da década de 1970, que era voltado para a experimentação (MARANDINO; SELLES; FERREIRA, 2009).

Reconhecemos que os conteúdos apresentados nos materiais didáticos de Ciências da Natureza do Projovem Urbano, quais sejam: "Gênero, sexualidade e cidadania"; "Sexo, prazer e atitude"; "Uso de drogas"; "Consumo de produtos químicos"; "Poluição ambiental", entre outros, são importantes de serem ensinados, e até admitimos que a proposta avança, se for comparada com os livros didáticos de ciências distribuídos atualmente para o "ensino regular", que também são voltados para o público de jovens e adolescentes, mas não enfocam uma perspectiva cidadã.

Nesse aspecto, colocamos sob suspeita a formação docente no curso de Licenciatura em Ciências Biológicas, e reiteramos que, em sua maior parte, ela direciona uma prática pedagógica que não contempla a EJA, e, desse modo, os conteúdos supracitados não fazem parte da formação inicial dos(as) licenciandos(as).

\section{Considerações finais}

Consideramos que a questão do currículo e a da prática docente, tendo em vista o atendimento educacional $\operatorname{dos}(\mathrm{as})$ alunos(as) da EJA, tornam-se questões centrais para a efetivação do direito à educação escolar, e foi o que procuramos apontar no presente artigo. Desse modo, esperamos que este texto possa contribuir significativamente para a elaboração de novas perspectivas, olhares, pesquisas, tanto no campo do currículo, quanto na formação de professores e na Educação em Ciências. 
Pensar na formação de professores(as) e no currículo da EJA nos faz refletir sobre a história e também o futuro desse público, já que vivemos um presente que se mostra assolador: precariedade desde a formação inicial nos cursos de Licenciatura, passando pelas condições de trabalho e infraestrutura, assim como a ameaça constante de fechamento de turmas.

Porém, seguindo o pensamento freireano, é necessário manter o otimismo e esperançar. Resistir, insurgir e apostar na criação e invenção de novas possibilidades de ensinar e aprender na e para a EJA, desde a formação inicial e continuada de professores à prática pedagógica no cotidiano escolar, priorizando sempre suas singularidades.

No que se refere ao Projovem Urbano, acreditamos ser este um programa que apresenta uma determinada concepção relativa à função social da educação e a qual cidadão o Programa propõe formar. No entanto a dimensão da cidadania que é mostrada é a de conquista de direitos, já que o Programa foi pensado para uma parcela da população que se encontra em situação de exclusão, vulnerabilidade e sem acesso a direitos sociais básicos.

Consideramos que o Projovem Urbano consegue alavancar uma proposta curricular inovadora, que contribui para a formação cidadã desses jovens que foram excluídos de direitos próprios e singulares de um cidadão. No que diz respeito ao ensino de Ciências, especificamente, o programa necessita trazer uma formação que pense, além do "minicientista", o cidadão preocupado, atuante, atento aos problemas sociais que o cercam cotidianamente, e que esse sujeito possa enxergar o papel da ciência vinculado aos interesses e participação da sociedade.

À guisa de considerações finais, é pertinente abordar que o que foi apresentado no presente artigo abre possibilidades de discussões que pretendemos publicar em outros artigos, destacando o Projovem do Campo e o cotidiano escolar, bem como a sociologia das ausências e emergências que ocorrem no curso de preparação para ingresso na universidade, voltado para pessoas jovens e adultas negras.

Reiteramos que a universidade do século XXI seja aquela que se engaje na EJA não apenas para ensinar, mas para aprender e para romper com o epistemicídio. Sendo assim, retomar a discussão sobre as possibilidades da formação inicial em EJA, ainda, prioritário e urgente. 


\section{Referências}

BARZANO, M. A. L. Currículo das margens: apontamentos para ser professor de ciências e biologia. Educação em Foco, Juiz de Fora, v.21, p.105-124, 2016. Disponível em:

https://periodicos.ufjf.br/index.php/edufoco/article/view/19658. Acesso em: 25 fev.2018.

CASSAB, M. Educação de jovens e adultos, educação em ciências e currículo: diálogos potentes. Educação em Foco, Juiz de Fora, v.21, n.1, p.13-38, mar./jun.2016. Disponível em: https://periodicos.ufjf.br/index.php/edufoco/article/view/19653. Acesso em: 25 fev.2018.

COSTA, G. S. S.; LIMA, R. A.; BRAGA, A. G. S. O ensino de botânica na EJA: um estudo de caso no Município de Porto Velho-RO. In: CONGRESSO NACIONAL DE BOTÂNICA, 64., 2013, Belo Horizonte. Anais [...]. Belo Horizonte, 2013.

FLORES, A. S. Os segredos das flores dos lavrados: relato de uma ação educativa na área de botânica no extremo norte do Brasil. Boletim do Museu Integrado de Roraima, v.8, n.1, p.10-18, 2014. Disponível em: https://periodicos.uerr.edu.br/index.php/bolmirr/article/view/764. Acesso em:15 jan.2017.

FREIRE, P. Pedagogia da esperança: um reencontro com a pedagogia do oprimido. São Paulo: Paz e Terra, 1994.

KRASILCHIK, M.; MARANDINO, M. Ensino de ciências e cidadania. 2. ed. São Paulo: Moderna, 2007.

LIMA. I. K. F. Uma exposição botânica: produção e significados de estudantes da educação de jovens e adultos de uma escola pública de Feira de Santana. 74f. Trabalho de Conclusão de Curso (Graduação em Ciências Biológicas) - Universidade Estadual de Feira de Santana, Feira de Santana, 2017.

MARANDINO, M.; SELLES, S. E.; FERREIRA, M. S. Ensino de biologia: histórias e práticas em diferentes espaços educativos. São Paulo: Cortez, 2009.

OLIVEIRA, I. B. Reflexões acerca da organização curricular e das práticas pedagógicas na EJA. Educar, Curitiba, n.29, p.83-100, 2007. Disponível em: https://www.scielo.br/scielo.php?pid=S010440602007000100007\&script=sci_abstract\&tlng=pt. Acesso em: 08 ago. 2018.

REIS, P.S. A formação de professores e o ensino de ciências biológicas: um olhar sobre a práxis docente na educação de jovens e adultos. Revista da SBEnBIO, n.5, 2012. Disponível em: sbenbio.org.br/wp-content/upload/edições/revista_sbenbio_n5/busca.html. Acesso em: 16 set. 2017. 
SALGADO, M. U. C.; AMARAL, L. A. Manual do educador: orientações gerais. Brasília: Programa Nacional de Inclusão de Jovens - Projovem Urbano, 2012.

SANTOS, B. S. A universidade no século XXI: para uma reforma democrática e emancipatória da Universidade. São Paulo: Cortez, 2004.

SANTOS, B. S. Pela mão de Alice: o social e o político na pós-modernidade. Campinas: Cortez, 1996.

Recebido em fevereiro 2020.

Aprovado em outubro 2020.

Periódico Horizontes - USF - Itatiba, SP - Brasil - e020059 